J. Lake Sci. (湖泊科学) , 2019, 31(2): 469-481

DOI 10. 18307/2019. 0216

(c) 2019 by Journal of Lake Sciences

\title{
高坝对乌江下游底栖动物群落结构的影响"
}

\author{
池仕运, 陈 胜, 李嗣新, 汪红军, 周连凤, 赵先富, 郑金秀, 胡 俊, 胡菊香* \\ (水利部中国科学研究院水工程生态研究所,水利部水工程生态效应与生态修复重点实验室,武汉 430079)
}

\begin{abstract}
摘 要: 基于 2006-2016 年近 10 年的长期监测数据,对乌江下游两座高坝的修建对底栖动物群落结构的影响效应进行 研究. 结果表明: 大坝蓄水前后底栖动物群落结构发生显著变化, 不同时期的群落结构差异明显. 蜉蝣目稚虫对生境的剧 烈变动不适应, 软体动物田螺科和觹螺科的一些种类对生境的剧烈扰动较为适应, 生活史较短的机会主义物种在水库淹 没区和坝下河段逐渐定殖下来. 建坝以及大坝的运行调度对乌江下游底栖动物的群落结构产生了重大影响, 底栖动物群 落结构随着时间发生一定程度的演替. 在底栖动物所有类群中, 软体动物对栖息地的丧失以及流量的剧烈波动具有较高 的耐受性, 水生昆虫相对较不耐受环境的剧烈变化, 而甲壳动物的适应性极强. 百分比模式相似性指数 (Percent Model Affinity, $P M A$ ) 的变动趋势可有效地反映大坝对底栖动物群落的影响效应, 其均值随离坝距离的增加而呈现逐步增加的趋 势, 表明大坝调度对水生态造成的负面影响会随着离坝距离的增加而逐步弱化, 这与河流不连续体理论 (Serial Discontinuity Concept, SDC) 的预测趋势基本一致. 根据长期监测成果, 蜉蝣目扁蜉科、四节蜉科、细裳蜉科以及毛翅目纹 石蛾科的种群恢复状况以及 $P M A$ 指数可作为评估大坝不利影响减缓措施效果的依据.
\end{abstract}

关键词: 底栖动物; 群落结构; 高坝; 不连续体理论; 演替;乌江

\section{Effects of high-head dams on macroinvertebrate communities in the lower reaches of Wu- jiang River}

CHI Shiyun, CHEN Sheng, LI Sixin, WANG Hongjun, ZHOU Lianfeng, ZHAO Xianfu, ZHENG Jinxiu, HU Jun \& HU Juxiang **

(Key Laboratory of Ecological Impacts of Hydraulic-projects and Restoration of Aquatic Ecosystem, Ministry of Water Resources; Institute of Hydrogeology, MWR \& CAS, Wuhan 430079, P.R. China)

\begin{abstract}
Based on the long-term monitoring data in the lower reaches of Wujiang River during 2006-2016, the effects of two high-head dams on macroinvertebrate communities were explored. Our results showed that the communities changed significantly before and after impoundment. Mayflies could not adapt to the drastic changes in habitats but some taxa from the families Viviparidae and Hydrobiidae could adapt to it. The opportunistic species with short life cycles colonized in the inundation areas of reservoirs and the river reaches below dams. Dam construction and operation had strong impacts on the macroinvertebrate communities, resulting in the community succession at a certain degree. Among the main groups, mollusks and crustaceans were tolerant to the drastic flow fluctuations and the loss of habitat, but aquatic insects were not tolerant to it. Our results showed the change trends of PMA (Percent Model Affinity) could effectively reflect the dam effects on macroinvertebrate communities. The average scores of $P M A$ increased with the distance to dams, suggesting the negative effects induced by dam construction and operation were gradually weaken with the increase of distance, it was consistent with the prediction of serial discontinuity concept (SDC). According to the longterm monitoring results, the population dynamics and restoration status of the families Heptageniidae, Baetidae, Leptophlebiidae and Hydropsychidae, and the biological index PMA could be used to evaluate the mitigation measures against the adverse effects induced by dam construction and operation in future.
\end{abstract}

Keywords: Macroinvertebrates; communities; high-head dam; serial discontinuity concept; succession; Wujiang River

* 国家自然科学基金项目(51409178)、国家重点基础研究发展计划专项(2017YFC0405303)和典型大城市水库水源 地水环境质量评估项目 (KFJ-SW-YW036) 联合资助. 2018-06-16 收稿;2018-08-29 收修改稿. 池仕运 (1979 ), 男,硕士,副研究员; E-mail:58249448@qq.com.

** 通信作者; E-mail: hujuxiang2005@163.com. 
乌江是长江右岸最大的支流, 全长 $1037 \mathrm{~km}$, 总落差 $2124 \mathrm{~m}$, 流域面积 $87920 \mathrm{~km}^{2}$, 年径流量与黄河相当, 是我国 12 大水电基地之一. 根据流域规划, 乌江干流规划 12 个梯级电站. 截止目前为止, 乌江干流自上游 至下游已建成 11 个梯级电站, 分别为普定、引子渡、洪家渡、东风、索风营、乌江渡、构皮滩、思林、沙沱、彭水 和银盘 ${ }^{[1-4]}$. 位于乌江下游的彭水和银盘水电站为首尾相连的梯级电站, 是乌江干流的第 10 级和第 11 级电 站, 分别开建于 2005 年和 2007 年, 分别关闸蓄水于 2008 年 1 月和 2011 年 4 月. 至此, 这两座水电站将乌江 下游原有连续的河流生态系统分隔成不连续的环境单元, 造成了生境的破碎, 库区范围内原急流开放型水 生态系统转变为峡谷河道型水库生态系统 ${ }^{[5-6]}$, 而坝下河段水文节律则受大坝调度所调控, 水位和流量波动 效应明显 ${ }^{[7]}$. 建坝引起的生境破碎、河道阻隔以及水文节律剧变导致鱼类的基因交流受阻、遗传多样性降 低、产卵场破坏和生活史无法完成, 以及其他水生生物类群发生变化进而引起食物网结构的改变 ${ }^{[2,5-8]}$. 研究 表明高坝的修建深刻地改变了河流的水文节律和自然形态, 导致河流从一个连续的生态系统转变成间断的 不连续生态系统, 这必然影响其间水生生物的生长、发育和繁殖, 甚至导致某一类种群濒危以至灭绝 ${ }^{[9-10]}$.

底栖动物是河流生态系统的重要组成部分, 是食物链的中间环节, 其群落结构的演替规律对水生态系 统状态具有重要的指示意义 ${ }^{[11]}$. 关于高坝 (坝高大于 $15 \mathrm{~m}$ ) 对河流底栖动物群落结构的影响效应, 国外的研 究案例较多,多集中于北美地区 ${ }^{[12-13]}$ 、欧洲 ${ }^{[14-15]}$ 以及澳洲 ${ }^{[16-17]}$. 国内关于大坝对河流底栖动物的影响研究报 道偏少, 且大坝类型多局限于低坝以及低坝头小水电上 ${ }^{[18-21]}$, 鲜有高坝对河流底栖动物群落结构影响效应 的相关研究报道. 本文选取乌江下游河段近 10 年的历史监测数据, 分析高坝建设前后以及不同时期底栖动 物群落结构的变化和演替趋势, 并采用百分比模式相似性指数 (Percent Model Affinity, PMA) 对高坝的影响 效应进行定量评估, 以期加深人们对水电工程引起的水生态效应的认识.

\section{1 材料与方法}

\section{1 研究区域}

乌江发源于贵州西部威宁县乌蒙山, 流经黔北及渝东南, 在重庆市涪陵区注人长江. 六冲河汇口以上为 上游, 汇口至思南为中游, 思南以下为下游. 乌江水系呈羽状分布, 流域地势西南高, 东北低, 流域内喀斯特 发育. 地形以高原、山原、中山及低山丘陵为主. 由于地势高差大,切割强, 自然景观垂直变化明显. 以流急、 滩多、谷狭而闻名于世. 流域处于典型的亚热带湿润季风气候区 ${ }^{[22-24]}$. 本研究中, 研究区域涵盖乌江下游自 龚滩至涪陵的部分河段, 该河段在 2005-2011 年建成有两座高坝大型电站, 分别为彭水水电站和银盘水 电站.

彭水水电站坝址位于重庆市彭水县万足乡, 大坝为混凝土重力坝, 坝高 $116.5 \mathrm{~m}$, 坝址以上流域面积 $69000 \mathrm{~km}^{2}$, 占乌江流域总面积的 78.5\%. 流域多年平均降水量 $1160 \mathrm{~mm}$, 坝址多年平均流量 $1300 \mathrm{~m}^{3} / \mathrm{s}$, 年径 流量 410 亿 $\mathrm{m}^{3}$. 年平均含沙量 $0.354 \mathrm{~kg} / \mathrm{m}^{3}$, 正常蓄水位 $293 \mathrm{~m}$, 死水位 $278 \mathrm{~m}$, 调节库容 5.18 亿 $\mathrm{m}^{3}$, 为季调 节水库. 开发任务是以发电为主, 其次是航运、防洪及其他综合利用. 水库回水至贵州省沿河县城, 长约 117 $\mathrm{km}$, 为峡谷河道型水库 ${ }^{[2,5-6]}$. 银盘水电站位于重庆市武隆县江口镇附近, 坝址控制流域面积 $74910 \mathrm{~km}^{2}$, 上游 接彭水水电站, 下游为白马梯级, 是兼顾彭水水电站的反调节任务和渠化航道的枢纽工程. 水库正常蓄水位 $215 \mathrm{~m}$, 总库容 3.2 亿 $\mathrm{m}^{3}$, 大坝为混凝土重力坝, 坝高 $80 \mathrm{~m}$, 正常蓄水位 $215 \mathrm{~m}$, 死水位 $211.5 \mathrm{~m}$, 库水位每天在 正常蓄水位 $215 \mathrm{~m}$ 和死水位 $211.5 \mathrm{~m}$ 之间变化, 为日调节水库 (图 1).

\section{2 断面设置}

底栖动物数据来自彭水水电站和银盘水电站长期生物监测计划 (2006- 2015 年) 以及 2016 年的补充调 查. 从上游至下游共设置 10 个监测断面, 分别为龚滩 $\left(1^{\#}\right)$, 洪渡乌江 $\left(2^{\#}\right)$ 、鹿角 $\left(3^{\#}\right)$ 、万足 $\left(4^{\#}\right)$ ( 位于和靠 近彭水水电站坝下)、彭水 $\left(5^{*}\right) 、$ 银盘 $\left(6^{*}\right)$ 、蔡家嘴 $\left(7^{*}\right)$ (位于和靠近银盘坝下)、江口 $\left(8^{*}\right) 、$ 中咀 $\left(9^{\#}\right)$ 和武隆 $\left(10^{\#}\right)$. 采样时段为一年中的平水期 ( $4-5$ 月)、丰水期 ( $7-8$ 月) 和枯水期 (11-12 月). 采样年份分为 3 个 时期, 分别为大坝蓄水前 (2006-2007 年), 蓄水后第一时期 (2008-2010 年) 和蓄水后第二时期 ( $2011-$ 2016 年). 蓄水前, 研究河段的所有采样断面均保持天然河流形态 (图 2A 和图 2B), 蓄水后第一时期彭水坝 上断面龚滩、洪渡乌江和鹿角已为彭水水库所淹没, 成为库区的一部分, 而彭水坝下断面万足坝下、彭水、银 盘、蔡家嘴、江口、中咀和武隆则受彭水大坝的调度影响, 水位和流量日波动效应明显, 水位落差可达 $6 \mathrm{~m}$ (图 


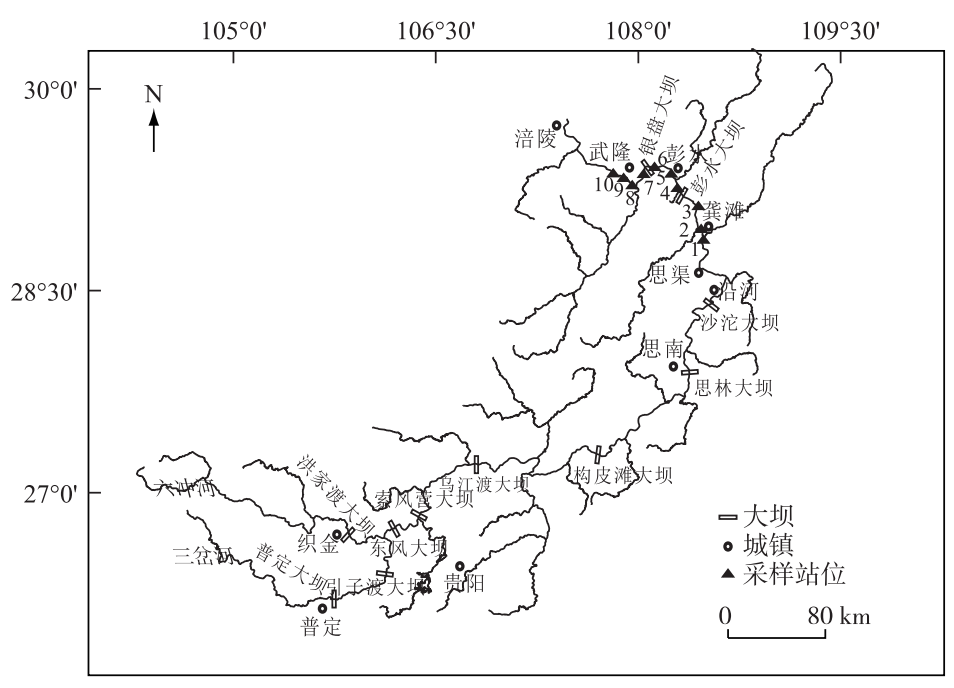

图 1 乌江流域图及采样站位

Fig. 1 Sampling sites in Wujiang River Basin

2C), 从而在河床沿岸形成面积较大的消落带. 在蓄水后第二时期,随着银盘水库于 2011 年 4 月下闸蓄水, 靠近银盘坝址的银盘断面成为水库的一部分, 水库回水延伸到彭水断面, 导致彭水断面成为银盘水库库尾 的一部分, 而银盘坝下断面蔡家嘴、江口、中咀和武隆不再受彭水大坝调度的影响, 主要受银盘水库调度的 影响, 水位和流量波动效应明显, 水位落差可达 $7 \mathrm{~m}$ (图 2D), 河床沿岸带形成较大面积的消落带. 因此 10 个 采样断面可根据水电站的影响程度分为 4 个区域, 区域 1 (龚滩、洪渡乌江和鹿角) 在彭水水库蓄水后主要受 水库蓄水影响; 区域 2(万足坝下) 在 2008-2016 年一直受彭水大坝调度的影响; 区域 3(彭水和银盘) 在 2008-2010 年受彭水大坝调度的影响, 在 2011-2016 年受银盘水库淹没的影响 ; 区域 4(蔡家嘴、江口、中咀 和武隆) 在 2008-2010 年受彭水大坝调度的影响,在 2011-2016 年则受银盘大坝调度的影响.

\section{3 数据收集与处理}

底栖动物的采样工具为标准踢网 $(30 \mathrm{~cm} \times 30 \mathrm{~cm})$ 或改良 Surber 网 $(35 \mathrm{~cm} \times 45 \mathrm{~cm})$, 采样时间限定为 5 $\min ^{[24]}$. 采样河段由于流速较快和流量较高, 底质主要为岩性河床和巨型石块,难以准确定量采集,因此密度 和生物量未进行计算. 底栖动物样品在野外经清水洗涤后简单分拣后装入宽口塑料瓶中用 $4 \%$ 的福尔马林 液进行保存. 样品送人实验室后用体式解剖镜 (莱卡 EZ4D, 德国) 和显微镜 (奥林巴斯 BH-2, 日本) 进行镜 检. 由于项目实施时间较长, 样品鉴定人员中间有更迭, 为减少数据误差, 对标本鉴定水平进行降级处理, 即 所有样品均鉴定到科或由属种级降为科级水平, 这也是不同实验室进行数据整合所常用的方法, 因为底栖 动物鉴定到科级水平完全能够满足生态学研究需要 ${ }^{[25-26]}$. 多元统计分析采用 PC-Ord v6.19 软件, 基本统计 分析则采用 SPSS v22.0 软件.

计算各站位的百分比模式相似性指数 $P M A^{[27]}$, 其公式为: $P M A=100-0.5 \sum|a-b|$, 式中, $a$ 为底栖动物 各类群在样点中实际所占百分比, $b$ 为底栖动物各类群在模型中所占百分比. 以乌江 PMA 修正模型为依据 计算各站位 $P M A$ 分值, 分值越高表明该站位受到的胁迫越小, 其生态状态越接近建坝前. 修正模型中底栖 动物七大类群数量所占百分比见表 $1^{[24]}$.

采用 Bray-Curtis 相似性指数绘制双序图来揭示不同区域不同时期底栖动物群落结构的差异. 采用多响 应置换过程分析 (Multi Response Permutation Procedure, MRPP) 检验不同时期的底栖动物群落结构差异的显 著性. 采用指示种分析 (Indicator Species Analysis, ISA) 来探讨不同时期底栖动物的指示分类单元. 多元分 析前, 将不同区域各站位不同时期的样本数据进行百分比转换以消除采样努力量的差异影响 ${ }^{[28]}$. 

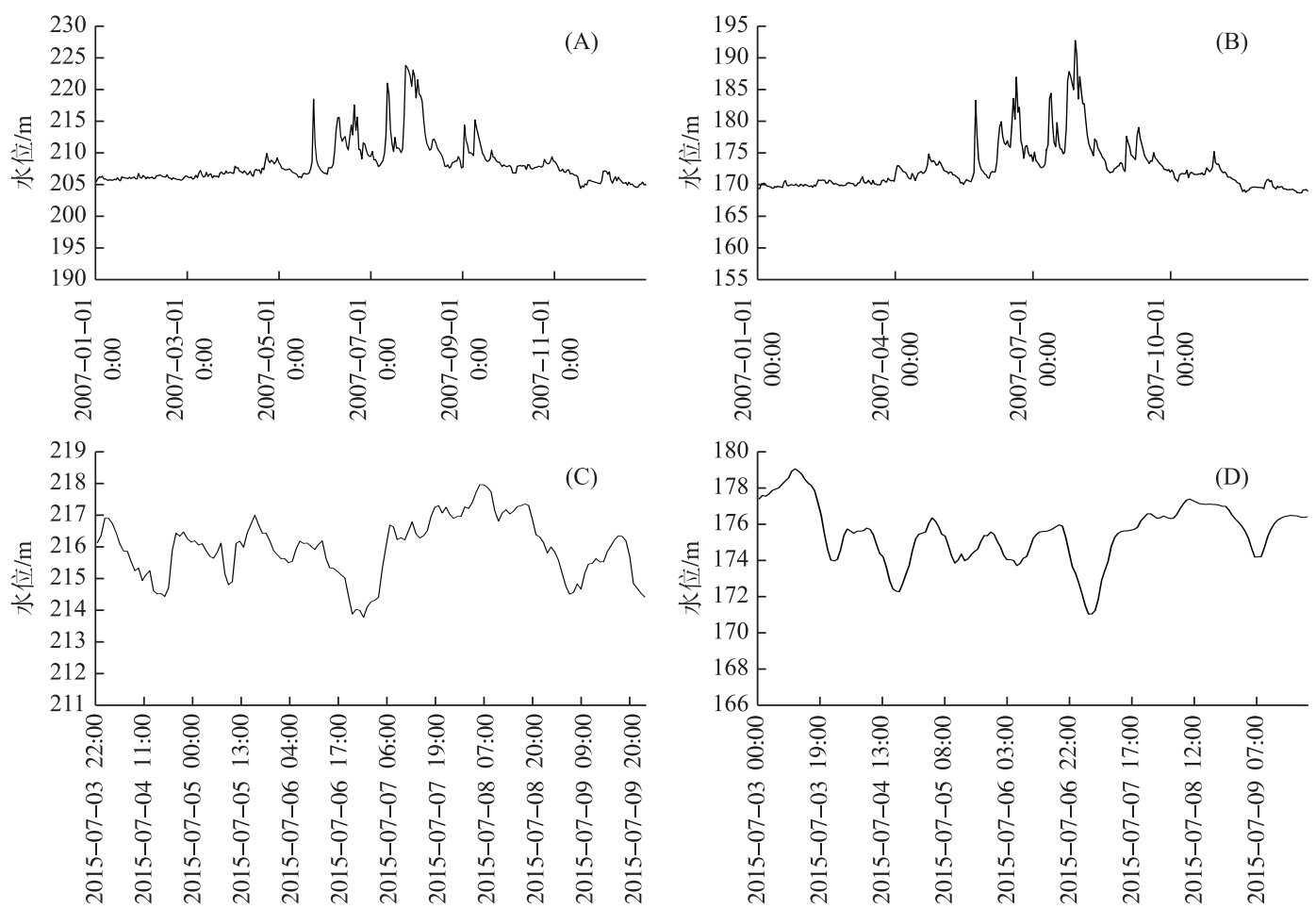

图 2 彭水水文站和武隆水文站水位波动(建坝蓄水前(2007 年) 彭水 (A) 和武隆 (B) 水文站一年的 水位变动, 蓄水后 (2015 年) 彭水 $(\mathrm{C})$ 和武隆 $(\mathrm{D})$ 水文站 7 月一周内的水位变动)

Fig. 2 The water level fluctuations of Pengshui and Wulong hydrologic stations

( A-the water level fluctuations of Pengshui station within 2007 before impounding; B-the water level fluctuations of Wulong station within 2007 before impounding; C-the water level fluctuations of Pengshui station within a week in July, 2015 after impounding; D-the water level fluctuations of Wulong station within a week in July, 2015 after impounding)

表 1 PMA 修正模型中底栖 动物七大类群数量占比

Tab. 1 The percentages of seven macroinvertebrate groups based on the modified PMA

\begin{tabular}{lc}
\hline 类群 & 数量占比 $/ \%$ \\
\hline 蜉蝣目 & 49.9 \\
襀翅目 & 0 \\
毛翅目 & 24.8 \\
鞘翅目 & 0.8 \\
摇蚊科 & 8.3 \\
寡毛类 & 0.2 \\
其他类群 & 16.1 \\
\hline
\end{tabular}

\section{2 结果与分析}

\section{1 群落结构的时空变化}

自 2006- 2016 年共采集了 153 个有效样本,鉴定出 63 科. 大 坝蓄水前 $(2006-2007$ 年) 检出底栖动物 34 科, 常见科为四节蜉科 和扁蜉科, 出现频次分别为 $60.87 \%$ 和 $69.57 \%$. 就数量百分比而言, 前 5 位优势单元为田螺科 ( $29.34 \%$ )、蚬科 ( $28.12 \%$ )、扁蜉科 $(8.87 \%)$ 、纹石蛾科 $(8.21 \%)$ 和觹螺科 $(7.65 \%)$. 蓄水后第一时期 (2008-2010 年) 检出 33 科, 常见科为觹螺科和贻贝科, 出现频次 分别为 $65.79 \%$ 和 $57.89 \%$, 就数量百分比而言, 前 5 位优势单元为觹 螺科 (33. $38 \%$ ) 、贻贝科 (29.94\%) 、颤蚓科 ( $6.83 \%$ )、钩虾科 $(6.78 \%)$ 和扁蜉科 $(5.77 \%)$. 蓄水后第二时期 (2011-2016 年) 检出 底栖动物 46 科, 常见科为摇蚊科、颤蚓科和觹螺科, 出现频次分别 为 $76.09 \% 、 47.83 \%$ 和 $46.74 \%$, 就数量百分比而言, 前 5 位优势单元

为摇蚊科 $(24.41 \%)$ 、田螺科 $(20.76 \%)$ 、觹螺科 $(13.00 \%)$ 、椎实螺科 $(8.69 \%)$ 和长臂虾科 $(6.02 \%)$.

不同时期的底栖动物群落结构差异显著 (MRPP, $T=-16.57, A=0.053, P<0.001)$. 根据 ISA 分析结果, 
蓄水前 (2006-2007 年) 指示分类单元为四节蜉 科、扁蜉科、纹石蛾科、带丝蚓科和田螺科. 蓄水 后第一时期 $(2008-2010$ 年) 指示分类单元为贻 贝科和觹螺科. 蓄水后第二时期 $(2011-2016$ 年) 指示分类单元为摇蚊科、颤蚓科、匙指虾科和 水蚟科.

大坝蓄水前软体动物是绝对优势类群,数量 占比高达 70.94\%, 蓄水后第一时期软体动物依 然占绝对优势地位, 占比达 $71.56 \%$, 蓄水后第二 时期软体动物数量占比有所下降, 数量占比降至 $53.87 \%$, 而水生昆虫则上升至 $32.46 \%$, 相比前两
表 2 研究区域底栖动物不同类群 在不同时期的数量占比

Tab.2 The percentages of macroinvertebrate groups in different periods in the study area

\begin{tabular}{lccc}
\hline 类群 & $2006-2007$ 年 & $2008-2010$ 年 & $2011-2016$ 年 \\
\hline 软体动物 & $70.94 \%$ & $71.56 \%$ & $53.87 \%$ \\
水生昆虫 & $26.51 \%$ & $13.37 \%$ & $32.46 \%$ \\
甲壳动物 & $1.39 \%$ & $7.07 \%$ & $7.59 \%$ \\
寡毛类 & $1.05 \%$ & $7.75 \%$ & $5.91 \%$ \\
其他类群 & $0.11 \%$ & $0.24 \%$ & $0.17 \%$ \\
\hline
\end{tabular}
个时期, 上升近 10\% 20\%. 甲壳动物由蓄水前的 $1.39 \%$ 上升至蓄水后第二时期的 7.59\%, 寡毛类和其他类 群所占数量百分比相比蓄水前有所上升 (表 2).

从 Bray-Curtis 双序图中也可以看出, 区域 1(图 3A) 蓄水前后的底栖动物群落彼此分离, 经 MRPP 检验 差异达到显著水平 $(T=-15.33, A=0.197, P<0.001)$; 区域 2(图 3B) 蓄水前后的底栖动物群落分离较为明 显, 经 MRPP 检验差异达到显著水平 $(T=-2.76, A=0.051, P=0.014)$; 区域 3(图 3C) 的底栖动物群落蓄水 前与蓄水后第一时期的差异经 MRPP 检验达到显著水平 $(T=-1.88, A=0.078, P=0.036)$, 蓄水后第二时期

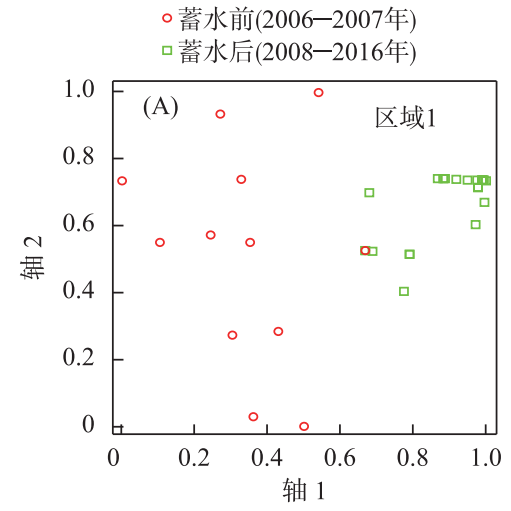

。蓄水前(2006-2007年)

口蓄水后第一时期(2008-2010年)

+蓄水后第二时期(2011-2016年)

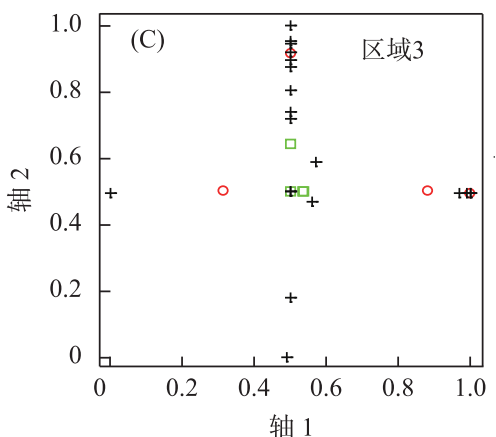

。蓄水前(2006-2007年)

蓄水后(2008-2016年)

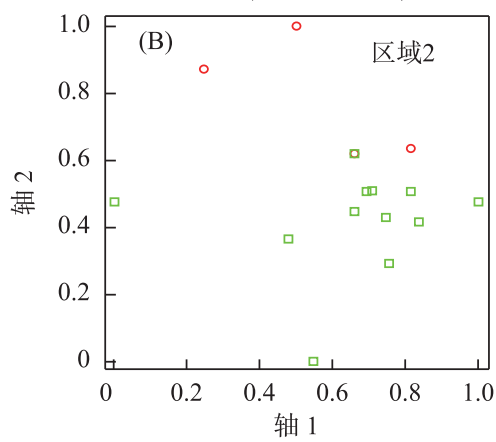

。蓄水前(2006-2007年)

口蓄水后第一时期(2008-2010年)

+ 蓄水后第二时期(2011-2016年)

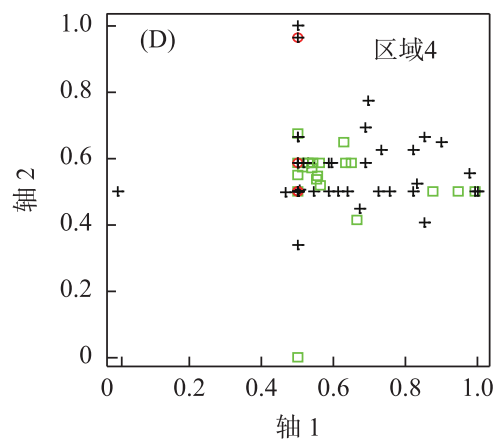

图 3 乌江彭水水电站影响河段不同区域基于底栖动物数据的 Bray-Curtis 双序图

Fig.3 The Bray-Curtis biplots based on macroinvertebrate data in different areas in the river reaches affected by Pengshui hydrologic station Dam in Wujiang River 
与蓄水后第一时期群落结构的差异也达到显著水平 $(T=-1.94, A=0.031, P<0.05)$, 但蓄水后第二时期与蓄 水前的群落结构差异反而缩小, 未达到显著水平 $(T=-0.23, A=0.004, P=0.314)$; 区域 4(图 3D) 的底栖动 物群落结构蓄水后第一时期与蓄水前相比, 差异未达显著水平 ( MRPP $, T=-1.43, A=0.023, P=0.090)$, 蓄 水后第二时期群落结构与蓄水后第一时期差异达到显著水平 ( MRPP, $T=-2.72, A=0.012, P=0.019)$, 与蓄 水前相比差异也显著 (MRPP $, T=-2.24, A=0.014, P=0.036)$.

各区域不同时期底栖动物指示分类单元见表 3 , 从表 3 可以看出, 区域 1 蓄水前的主要指示分类单元为 扁蜉科、四节蜉科、田螺科、带丝蚓蛾科和纹石蛾科, 其观测指示值( Observed Indicator Value, $I V$ ) 均在 40 以 上, 蓄水后该区域的指示分类单元为摇蚊科和颤蚓科; 区域 2 蓄水前的指示分类单元为扁蜉科和四节蜉科, 蓄水后由于物种更替频繁,无指示分类单元; 区域 3 蓄水前的指示分类单元为四节蜉科,蓄水后第一时期的 指示分类单元为贻贝科; 蓄水后第二时期无指示分类单元; 区域 4 蓄水前的指示分类单元为带丝蚓科, 蓄水 后第一时期的指示分类单元为四节蜉科,蓄水后第二时期无指示分类单元.

表 3 不同区域不同时期底栖动物的指示物种分析

Tab.3 The indicator species analysis of macroinvertebrates from different areas in different periods

\begin{tabular}{|c|c|c|}
\hline 区域 & 时期 & 指示分类单元 \\
\hline \multirow[t]{11}{*}{ 区域 1} & 蓄水前 (2006-2007 年) & 扁蜉科 Heptageniidae $(I V=75, P=0.002)$ \\
\hline & & 四节蜉科 Baetidae $(I V=58.3, P=0.002)$ \\
\hline & & 田螺科 Viviparidae $(I V=58.3, P=0.002)$ \\
\hline & & 带丝蚓科 Lumbriculidae $(I V=41.7, P=0.0014)$ \\
\hline & & 纹石蛾科 Hydropsychidae $(I V=41.7, P=0.0016)$ \\
\hline & & 钩虾科 Gammaridae $(I V=33.3, P=0.0056)$ \\
\hline & & 椎实螺科 Lymnaeidae $(I V=33.3, P=0.007)$ \\
\hline & & 细裳蜉科 Leptophlebiidae $(I V=25, P=0.0224)$ \\
\hline & & 蚬科 Corbiculidae $(I V=38.7, P=0.0364)$ \\
\hline & 蓄水后 ( 2008-2016 年) & 摇蚊科 Chironomidae $(I V=82.2, P=0.0002)$ \\
\hline & & 颤蚓科 Tubificidae $(I V=69.7, P=0.001)$ \\
\hline \multirow[t]{2}{*}{ 区域 2} & 蓄水前 ( 2006-2007 年) & 扁蜉科 Heptageniidae $(I V=94.2, P=0.0016)$ \\
\hline & & 四节蜉科 Baetidae $(I V=75, P=0.0084)$ \\
\hline \multirow[t]{2}{*}{ 区域 3} & 蓄水前 ( 2006-2007 年) & 四节蜉科 Baetidae $(I V=100, P=0.0004)$ \\
\hline & 蓄水后第一时期 (2008-2010 年) & 贻贝科 Mytilidae $(I V=63.6, P=0.0174)$ \\
\hline \multirow[t]{2}{*}{ 区域 4} & 蓄水前 ( 2006－2007 年) & 带丝蚓科 Lumbriculidae $(I V=44, P=0.0086)$ \\
\hline & 蓄水后第一时期 (2008-2010 年) & 四节蜉科 Baetidae $(I V=29.4, P=0.0482)$ \\
\hline
\end{tabular}

就类群而言, 大坝蓄水前区域 1 软体动物是绝对优势类群, 数量占比高达 $75.79 \%$, 其次是水生昆虫, 占 比 $22.18 \%$, 蓄水后寡毛类和水生昆虫成为优势类群, 占比分别为 $47.26 \%$ 和 $50.47 \%$; 区域 2 蓄水前软体动物 和水生昆虫数量占比分别为 $51.52 \%$ 和 $42.42 \%$, 蓄水后软体动物占比上升至 $81.43 \%$, 水生昆虫占比则下降 至 $7.29 \%$; 区域 3 自蓄水后甲壳动物数量占比持续上升, 软体动物占比先升后降, 蓄水后第一时期占比高达 $84.11 \%$, 水生昆虫占比先降后升; 区域 4 寡毛类数量占比自蓄水后持续下降, 甲壳动物占比先升后降, 软体 动物占比持续下降, 水生昆虫占比则持续上升 (表 4).

\section{$2.2 P M A$ 分值的变化}

就不同区域而言, 区域 1 和区域 2 由于受彭水水库蓄水影响, 蓄水后 $P M A$ 分值显著下降 (图 4A), 区域 3 自蓄水后受彭水大坝调度的影响以及银盘电站蓄水的影响, $P M A$ 分值下降较为明显; 区域 4 蓄水后第二时 期相比蓄水后第一时期, $P M A$ 分值有所下降(图 4B). 就具体站位而言, 区域 1 和区域 2 的 4 个断面如龚滩、 洪渡乌江、鹿角和万足坝下, 蓄水后的 $P M A$ 分值要远低于蓄水前; 区域 3 的彭水断面 $P M A$ 平均分值先剧烈 下降后略有回升; 区域 4 的几个断面如蔡家嘴、江口、中咀和武隆, 蓄水后第二阶段与第一阶段相比, $P M A$ 平 均分值明显下降. 整体上来看, 蓄水后第一阶段 $(2008-2010$ 年) 和第二阶段 $(2011-2016$ 年) 的 $P M A$ 平均 分值均随离坝距离的增加而呈现逐步增加趋势 (图 5). 
表 4 区域 $1 \sim 4$ 底栖动物不同类群在不同时期的数量占比

Tab.4 The percentages of macroinvertebrate groups in different periods in areas 1 to 4

\begin{tabular}{|c|c|c|c|c|c|c|c|c|c|c|}
\hline \multirow[b]{2}{*}{ 类群 } & \multicolumn{2}{|c|}{ 区域 1} & \multicolumn{2}{|c|}{ 区域 2} & \multicolumn{3}{|c|}{ 区域 3} & \multicolumn{3}{|c|}{ 区域 4} \\
\hline & $\begin{array}{c}2006 \text { - } \\
2007 \text { 年 }\end{array}$ & $\begin{array}{l}2008 \text { - } \\
2016 \text { 年 }\end{array}$ & $\begin{array}{c}2006- \\
2007 \text { 年 }\end{array}$ & $\begin{array}{l}2008 \text { - } \\
2016 \text { 年 }\end{array}$ & $\begin{array}{c}2006 \text { - } \\
2007 \text { 年 }\end{array}$ & $\begin{array}{c}2008 \text { - } \\
2010 \text { 年 }\end{array}$ & $\begin{array}{c}2011- \\
2016 \text { 年 }\end{array}$ & $\begin{array}{c}2006 \text { - } \\
2007 \text { 年 }\end{array}$ & $\begin{array}{c}2008 \text { - } \\
2010 \text { 年 }\end{array}$ & $\begin{array}{l}2011- \\
2016 \text { 年 }\end{array}$ \\
\hline 寡毛类 & $0.56 \%$ & $47.26 \%$ & $3.03 \%$ & $0.40 \%$ & $2.09 \%$ & $1.32 \%$ & $5.34 \%$ & $7.50 \%$ & $1.97 \%$ & $2.71 \%$ \\
\hline 甲壳动物 & $1.33 \%$ & $0.00 \%$ & $3.03 \%$ & $10.88 \%$ & $0.42 \%$ & $6.62 \%$ & $37.09 \%$ & $5.00 \%$ & $9.51 \%$ & $2.41 \%$ \\
\hline 其他类群 & $0.14 \%$ & $0.38 \%$ & $0.00 \%$ & $0.00 \%$ & $0.00 \%$ & $0.66 \%$ & $0.59 \%$ & $0.00 \%$ & $0.28 \%$ & $0.09 \%$ \\
\hline 软体动物 & $75.79 \%$ & $1.89 \%$ & $51.52 \%$ & $81.43 \%$ & $48.12 \%$ & $84.11 \%$ & $30.27 \%$ & $82.50 \%$ & $70.07 \%$ & $64.02 \%$ \\
\hline 水生昆虫 & $22.18 \%$ & $50.47 \%$ & $42.42 \%$ & $7.29 \%$ & $49.37 \%$ & $7.28 \%$ & $26.71 \%$ & $5.00 \%$ & $18.17 \%$ & $30.78 \%$ \\
\hline
\end{tabular}
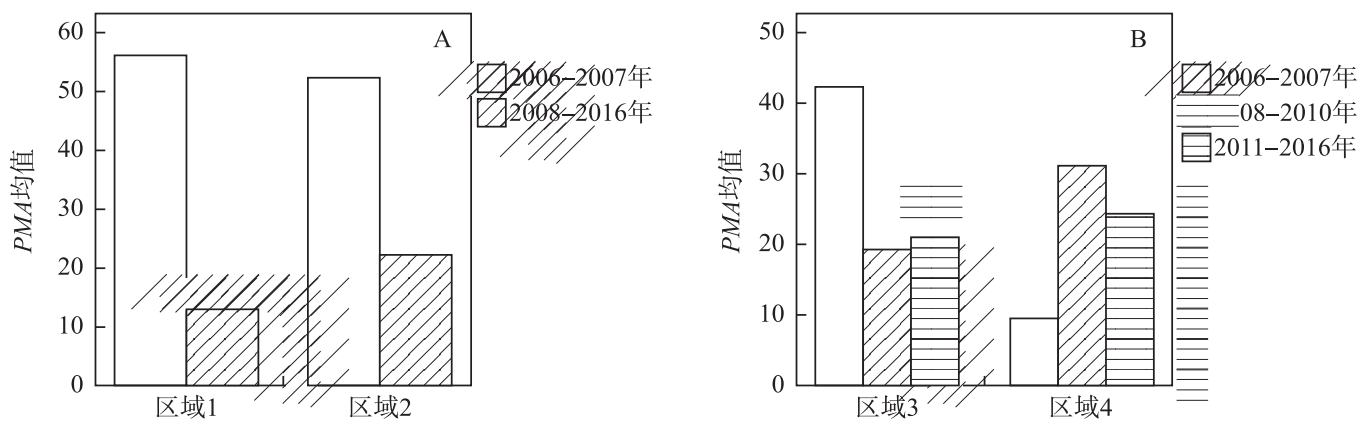

图 4 不同区域 $P M A$ 均值的变动趋势

Fig.4 The average PMA from different areas and their change trends

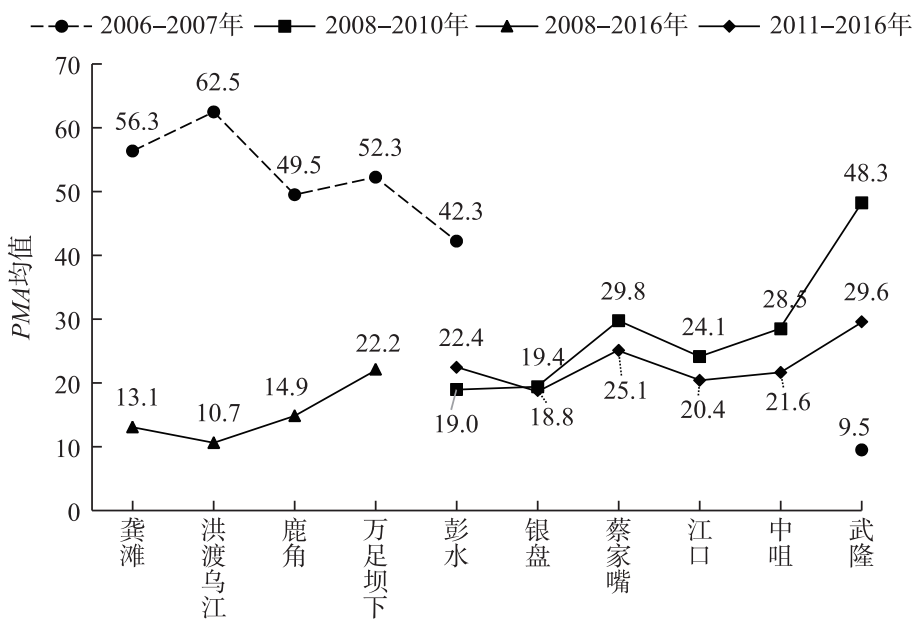

图 5 各监测站位 $P M A$ 平均分值及变动趋势

Fig.5 The average PMA of different sites and their change trends

\section{3 讨论}

大量研究表明河流建坝不仅改变了河流的水文地貌同时也改变了受影响河段的物种组成以及现存 量 ${ }^{[29-34]}$, 本研究的长期观测结果表明大坝蓄水前后底栖动物群落结构发生显著变化, 不同时期的群落结构 
差异明显, 在统计学上达到显著水平. 不同时期常见科和优势科的变化趋势表明, 乌江下游底栖动物中的蜉 蝣目稚虫对生境的剧烈变动不适应, 而软体动物田螺科和觹螺科的一些种类对生境的剧烈扰动如水位的快 速波动较为适应, 与此同时摇蚊科和颤蚂科的一些物种在水库淹没区和坝下河段逐渐定殖下来 ${ }^{[35-39]}$. 大坝 下游流量的快速变化会对下游河段的水生态系统造成短期和反复的干扰. 许多底栖动物对环境的适应具有 局限性, 大多数物种对流量的剧烈波动并不适应, 这会造成物种丰富度、多样性和生产力的降低 ${ }^{[40]}$. 如彭水 电站坝下河段不稳定的生境环境导致生活于该河段的底栖动物物种更替频繁, 除软体动物如田螺科的球河 螺 (Rivnlaria globosa)、觹螺科的卵圆仿雕石螺 (Lithwglyphopsis ovatus) 以及豆螺科的堇拟沼螺 (Assiminea violacea ) 能适应短暂的脱水现象外, 其余体型较小, 生活周期短, 实行 $r$-对策的机会主义物种 ${ }^{[41-42]}$, 如双翅目的 伪璚虹科、滨蝇科、蠓科、蝇科、水虹科、虹科、大蚊科的种类和摇蚊科的一些种类 (矮突摇蚊 (Nanocladius sp.)、直突摇蚊 (Orthocladius sp.)、拟矩摇蚊 (Paraphaenocladius sp.)、多足摇蚊 (Polypedilum sp.)、流水长跗摇 蚊 (Rheotanytarsus sp.)、长跗摇蚊 (Tanytarsus sp.)、环足摇蚊 (Cricotopus sp.)、开叉摇蚊 (Dicrotendipes sp.)、肛 齿摇蚊 (Neozavrella sp.)、隐摇蚊 (Cryptochironomus sp.) 和特维摇蚊 (Tvetenia sp.) 等) 在该河段短暂交替出现 ( 附录 1). 蜉蝣目扁蜉科的似动蜉 (Cinygmina sp.) 在两座大坝蓄水前为优势种, 蓄水后第一时期依然在彭水 坝下河段广泛存在, 随着银盘电站的蓄水, 其适宜生境被不断压缩, 在蓄水后第二时期已不常见. 彭水坝下 断面贻贝科的淡水壳菜 (Limnoperna fortunei) 在蓄水后第一时期大量滋生, 但随着时间的延长以及坝下河段 泥沙的沉积, 河床岩石缝隙逐渐被泥沙填塞, 石块的包埋度增加 ${ }^{[43]}$, 淡水壳菜的适宜生境逐渐萎缩, 在蓄水 后的第二时期种群规模衰退严重. 与此同时, 蓄水前的优势种田螺科的球河螺、觹螺科的卵圆仿雕石螺以及 豆螺科的堇拟沼螺反而能趋避于石块的㖓隙中经受短暂的脱水现象而存活下来. 活动能力较强的甲壳类如 长臂虾科的物种对水位的剧烈波动极为耐受,成为蓄水后的优势种群,在坝下河段极为常见.

大坝的修建运行会对大坝下游河段的物理、化学和生物特性造成影响, 如河道形态以及底质粒径发生 变化,处于不同调整期的河段具有代表性的种群结构,河流受到调控会导致原有激流生态系统发生一定程 度的演替 ${ }^{[15,44]}$. 研究区域各个时期底栖动物指示分类单元发生一定程度的变化, 表明建坝以及大坝的运行 调度对乌江下游底栖动物的群落结构产生了重大影响, 底栖动物群落结构随着时间的延长发生一定程度的 演替. 不同区域不同时期底栖动物的指示分类单元的变化也表明处于不同调整期的河段具有代表性的种群 结构. 蓄水前和蓄水后第一时期软体动物是底栖动物中的绝对优势类群, 数量占比超过 $70 \%$, 水生昆虫占比 下降 $10 \%$ 左右, 蓄水后第二时期软体动物数量占比有所下降,但仍占主导地位, 而水生昆虫则上升近 $20 \%$. 甲壳动物则呈稳步上升趋势, 由蓄水前的 $1.39 \%$ 上升至蓄水后第二时期的 $7.59 \%$. 从不同区域来看, 区域 2 和区域 4 软体动物数量占比在蓄水后占比依然很高, 高达 $60 \%$ 以上. 以上结果表明在底栖动物所有类群中, 软体动物对栖息地的丧失以及流量的剧烈波动具有较高的耐受性, 水生昆虫则相对较不耐受环境的剧烈变 化, 而甲壳动物几丁质外壳对体内脱水具有较强的抵御作用, 同时活动能力强, 可及时逃离不利生境, 因此 对环境的剧烈变化适应性极强 ${ }^{[45]}$.

就不同区域而言, 由于经受的胁迫因子不同, 底栖动物群落结构的演替和对生态环境变化的响应模式 不尽相同. 就区域 1 和区域 3 而言, 其受到的外界干扰主要是大坝建成蓄水后的淹没影响. 淹没不仅导致原 有河床底质发生根本性的转变, 水位也大大抬升, 底栖动物群落由原激流性河流种转变为典型的湖沼型静 水种 ${ }^{[4-47]}$. 区域 1 蓄水前田螺科、纹石蛾科、扁蜉科和四节蜉科数量占比分别为 $35.51 \% 、 10.11 \% 、 5.75 \%$ 和 $2.39 \%$, 蓄水后这几个科完全消亡, 蚬科也由蓄水前的 $35.44 \%$ 分别急剧下降到蓄水后的 $1.13 \%$, 与此同时摇 蚊科和颤蚂科占比由蓄水前的 $0.70 \%$ 和 $0.14 \%$ 分别急剧上升至 $47.45 \%$ 和 $47.26 \%$. 区域 3 的觹螺科由蓄水前 的 $45.19 \%$ 下降至蓄水后第二时期的 $16.20 \%$, 而扁蜉科则由蓄水前的 $26.78 \%$ 持续下降至蓄水后第二时期的 $0.59 \%$. 就区域 2 和区域 4 而言, 其受到的主要胁迫因子为大坝调度引起的水位剧烈波动以及日流量急剧变 化, 底栖动物的适宜生境由于水位的消涨而大大压缩, 该河段除了较为耐受短暂脱水现象的软体动物和一 些机会主义物种外, 蜉蝣目和毛翅目的物种几近绝迹, 即使偶有采到, 也很大可能是上游支流或小溪流漂流 下来的种群. 如区域 2 的四节蜉科数量占比蓄水前为 $27.27 \%$, 蓄水后则完全消亡, 而扁蜉科则由蓄水前的 $13.13 \%$ 降至蓄水后的 $0.13 \%$. 区域 4 的扁蜉科在蓄水后第二时期数量占比只有 $2.62 \%$, 而摇蚊科占比则高达 $21.28 \%$. 
研究表明流量的昼夜波动可造成底栖动物的物种数和丰度的下降, 而流量的稳定则对物种数和丰度的 增加有利 ${ }^{[48]}$, 流量的突然增加或减少可导致底栖动物漂流行为的大量发生,而与生境条件的变化无关 ${ }^{[49-51]}$. 在长期的观测中发现: 在蓄水后的第一时期银盘断面还没有被淹没时段, 由于水位的剧烈波动, 纹石蛾发生 大规模的漂流现象,并随水位的消涨而被搁浅在岩石表面或缝隙中 ${ }^{[52-53]}$, 尤其是在夏季经受高温暴晒后其 种群死亡率很高, 种群发生大规模衰退现象, 这也是纹石蛾科数量百分比在两座电站先后建成运行后剧烈 下降的根本原因. 如纹石蛾科数量百分比由蓄水后前的 $8.21 \%$ 降至蓄水后第一时期的 $1.55 \%$ 和蓄水后第二 时期的 $0.03 \%$. 研究表明, 毛翅目的多距石蛾科、摇蚊科和寡毛类对水位的昼夜波动及脱水较为耐受, 而毛 翅目的纹石蛾科以及蜉蝣目的扁蜉科则极不耐受 ${ }^{[54]}$, 我们也观测到万足坝下断面在蓄水后第二时期出现了 大量多距石蛾科种类、摇蚊科的一些种类以及臭毛类在该断面也较为常见, 建坝前较为常见的纹石蛾科和 扁蜉科的一些种类现阶段在该断面已很难受其踪迹,这与国外已有的研究案例较为接近 ${ }^{[39,54]}$.

区域 1 和区域 2 的 $P M A$ 均值在蓄水后急剧下降, 表明蓄水后的生态状况已远远偏离蓄水前, 其受到的 胁迫程度很高. 区域 3 的 $P M A$ 均值在蓄水前处于较高水平, 蓄水后第一、第二时期均处于较低水平, 表明蓄 水后第一时期彭水大坝调度引起的水位流量波动对生态系统的胁迫效应明显, 蓄水后第二时期由银盘水库 蓄水导致的淹没效应也很强烈. 区域 4 在蓄水前由于银盘电站的开工建设导致 $P M A$ 分值较低,但蓄水后第 二时期相较第一时期 $P M A$ 均值下降, 表明继彭水电站蓄水后银盘电站的负面调控效应超过了彭水电站. 以 上结果表明 $P M A$ 可有效地反映大坝对河流生态系统的影响效应. 从长期变动趋势来看, 无论是在蓄水后第 一阶段还是蓄水后第二阶段, 区域 4 的 $P M A$ 平均分值均随离坝距离的增加而呈现逐步增加趋势, 表明大坝 调度对水生态造成的负面影响会随着离坝距离的增加而逐步弱化 ${ }^{[45]}$, 这与河流不连续体 (Serial Discontinuity Concept, SDC) 理论的预测趋势基本一致 ${ }^{[55-56]}$.

研究表明, 大坝下游未受调控支流的汇人对坝下河段底栖动物种群的恢复具有积极作用, 可有效缓解 大坝的负面效应 ${ }^{[17.57-59]}$, 底栖动物种群恢复距离和程度与坝下汇人支流的规模有很大关系, 支流规模越大, 恢复距离越短 ${ }^{[57,60-61]}$. 大坝调控带来的不利影响以及坝下支流汇入带来的恢复效应是造成坝下河段底栖动 物种群不连续性的根本原因. 因此坝下支流的汇人对底栖动物种群的恢复以及减缓大坝的不利影响意义重 大. 建议对银盘大坝坝下河段重要支流进行详细调研, 一些支流上经济效应不高的水坝应予以拆除, 在恢复 支流生态的同时可减缓乌江干流高坝对水生态带来的不利影响. 坝下河段流量的不稳定可造成泥沙的沉积 以及着生藻类的过度生长, 进而导致河床生境异质性的降低, 这对底栖动物种群造成了不利影响, 特别是蜉 蝣目、鞘翅目、襀翅目、有巢石蛾以及蚋类 ${ }^{[39,62-64]}$. 此外,伴随流量剧烈波动的脱水现象对河流浅滩生境影响 很大, 可造成摇蚊类和有巢石蛾类种群的大幅度衰退, 较长时间的脱水可导致水生昆虫从浅水区向深水区 迁移, 进而深水区水生昆虫的密度远高于浅水区 ${ }^{[65-66]}$. 目前彭水和银盘大坝调度方式带来了坝下河段流量 的急剧波动, 这造成坝下河段底栖动物种群的大规模衰退, 建议在兼顾发电效益的同时采取优化策略稳定 坝下流量, 减少河流浅滩带的脱水时间间隔, 从而避免活动能力较差的水生昆虫搁浅而死亡, 尤其是气温较 高的夏季. 根据近十年的监测成果, 可将蜉蝣目扁蜉科、四节蜉科、细裳蜉科以及毛翅目纹石蛾科的种群恢 复状况以及 $P M A$ 指数作为评估减缓大坝不利影响措施效果的依据.

致谢: 水利部中国科学院水工程生态研究所的陈威、张俊芳、沈强、米玮洁、高少波、陈明秀等同志协助了部 分野外采样工作,在此一并表示感谢!

\section{4 附录}

附录 I 见电子版 (DOI: 10.18307/2019.0216).

\section{5 参考文献}

[ 1 ] Tai PL, Peng SQ. Expericenc in planning comprehensive development of Wujiang River water resources. Yangtze River, 1993, (4) : 19-21. [谭培伦, 彭善群. 乌江流域规划中水资源综合利用的若干经验. 人民长江, 1993, (4): 19-21.]

[ 2 ] Xiong MH, Shao K, Xu N et al. Prelimary study on population genetic structure of Onychostoma sima before and after closure of Pengshui hydropower station on Wujiang River. Journal of Hydroecology, 2013, 34(1): 69-75. [熊美华, 邵科, 
徐念等. 乌江彭水水电站截流前后白甲鱼群体遗传结构初步研究. 水生态学杂志, 2013, 34(1): 69-75.]

[ 3 ] Luo X, Zou J, Dai J et al. Study on the key technology of optimal regulation of hydropower station group on Wujiang River. Water Power, 2007, 33(10): 4-7. [罗小黔, 邹建国, 戴建炜等. 乌江流域水电站群优化调控关键技术应用研究. 水力发电, $2007,33(10): 4-7$.]

[ 4 ] Xia H, Jin ZH, Zou JG et al. Present situation of ecological operation of Wujiang River cascade hydropower stations. Sichuan Environment, 2010, 29(5): 14-18. [夏豪, 金泽华, 邹建国等. 乌江干流梯级电站生态调度现状分析. 四川 环境, 2010, 29(5): 14-18.]

[ 5 ] Shi F, Xu N, Xiong MH et al. Using microsatellite markers to assess the impacts by Pengshui hydropower station on Wujiang River on population genetic diversity in Pseudogyrincheilus procheilus. Journal of Hydroecology, 2009, 2(2) : 117121. [史方, 徐念, 熊美华等. 利用微卫星标记评估乌江彭水水电站对泉水鱼的遗传多样性影响. 水生态学杂志, 2009, 2(2): 117-121.]

[ 6 ] Yang Z, Zheng HT, Xiong MH et al. Variation characteristics of fish community structure and biodiversity in autumn before and after impoundment of Pengshui hydropower station. Environmental Science \& Technology, 2011, 34(8): 22-29. [ 杨 志, 郑海涛, 熊美华等. 彭水电站蓄水前后鱼类群落多样性特征. 环境科学与技术, 2011, 34(8): 22-29.]

[ 7 ] Xiong MH, Shi F, Xu N et al. A preliminary analysis of genetic diversity of population of Onychostoma sima in Wujiang River with microsatellite markers. Journal of Hydroecology, 2009, 2(2): 122-125. [熊美华, 史方, 徐念等. 微卫星标 记分析乌江流域白甲鱼群体的遗传多样性. 水生态学杂志, 2009, 2(2) : 122-125.]

[ 8 ] Chen MX, Hu JX, Zhao XF et al. Characters of community structure of the crustacean zooplankton in newly constructed Pengshui Reservoir of the Wujiang River. Journal of Hydroecology, 2011, 32(5): 37-42. [陈明秀, 胡菊香, 赵先富等. 彭水水库蓄水初期乌江下游浮游甲壳动物群落结构特征. 水生态学杂志, 2011, 32(5) : 37-42.]

[ 9 ] Quinn JW, Kwak TJ. Fish assemblage changes in an ozark river after impoundment: A long-term perspective. Transactions of the American Fisheries Society, 2003, 132(1) : 110-119. DOI: 10.1577/1548-8659(2003) 132<0110: FACIAO>2.0. $\mathrm{CO} ; 2$.

[10] Cao WX. Several issues related to the protection of fish resources in the Yangtze River Basin. Resources and Environment in the Yangtze Basin, 2008, 2(2) : 163-164. DOI:1004-8227(2008)02-0163-07. [曹文宣. 有关长江流域鱼类资源保护 的几个问题. 长江流域资源与环境, 2008, 2(2) : 163-164.]

[11] Liu JK ed. Advanced hydrobiology. Beijing: Science Press, 1999. [刘建康. 高级水生生物学. 北京: 科学出版 社, 1999.]

[12] Munn MD, Brusven MA. Benthic macroinvertebrate communities in nonregulated and regulated waters of the Clearwater River, Idaho, USA. River Research \& Applications, 1991, 6(1) : 1-11. DOI: 10.1002/rrr.3450060102.

[13] Voelz NJ, Ward JV. Biotic and abiotic gradients in a regulated high elevation Rocky mountain river. River Research \& Applications, 1989, 3(1) : 143-152. DOI: 10.1002/rrr.3450030114.

[14] Cortes RMV, Ferreira MT, Oliveira SV et al. Macroinvertebrate community structure in a regulated river segment with different flow conditions. River Research \& Applications, 2002, 18(4) : 367-382. DOI: 10.1002/rra.679.

[15] Greenwood M, Bickerton M, Gurnell A et al. Channel changes and invertebrate faunas below Nant-Y-Môch Dam, River Rheidol, Wales, UK: 35 Years On. River Research \& Applications, 1999, 15(1-3) : 99-112. DOI : 10.1002/( SICI) 10991646(199901/06) $15: 1 / 3<99$ : : AID-RRR530>3.0.CO;2-I.

[16] Pardo I, Campbell IC, Brittain JE. Influence of dam operation on mayfly assemblage structure and life histories in two south-eastern Australian streams. River Research \& Applications, 1998, 14(3) : 285-295. DOI: 10. 1002/( SICI) 10991646(199805/06) 14:33.3.CO;2-Y.

[17] Storey A, Edward D, Gazey P. Recovery of aquatic macroinvertebrate assemblages downstream of the Canning Dam, Western Australia. River Research \& Applications, 1991, 6(3) : 213-224. DOI: 10.1002/rrr.3450060306.

[18] Ful XF, Wu NC, Zhou SC et al. Impacts of a small hydropower plant on macroinvertebrate habitat and an initial estimate for ecological water requirement of Xiangxi River. Acta Ecologica Sinica, 2008, 28(5): 1942-1948. [傅小城, 吴乃成, 周淑婵等. 引水型电站对河流底栖动物栖息地的影响及生态需水量. 生态学报, 2008, 28(5) : 1942-1948.]

[19] Fu XC, Tang T, Jiang WX. Impacts of small hydropower plants on macroinvertebrate communities. Acta Ecologica Sinica, 2008, 28(1) : 45-52. [ 傅小城, 唐涛, 蒋万祥等. 引水型电站对河流底栖动物群落结构的影响. 生态学报, 2008, $28(1): 45-52$. 
[20] Guo WJ, Zhao WH, Wang ZH. Effects of cascade diversion- type hydropower stations on benthic macroinvertebrate communities. Journal of Yangtze River Scientific Research Institute, 2015, (6) : 87-93. [郭伟杰, 赵伟华, 王振华. 梯级引水 式水电站对底栖动物群落结构的影响. 长江科学院院报, 2015, (6) : 87-93.]

[21] Han MH, Yu HY, Zhou B et al. The impact of run-of stream dams on benthic macroinvertebrate assemblages in urban streams. Acta Ecologica Sinica , 2012, 32(2) : 380-385. DOI: 10.5846/stxb201012081751. [ 韩鸣花, 于海燕, 周斌等. 城市溪流中径流式低坝对底栖动物群落结构的影响. 生态学报, 2012, 32(2): 380-385.]

[22] Li S, Zhou L, Wang H et al. Short-term impact of reservoir impoundment on the patterns of mercury distribution in a subtropical aquatic ecosystem, Wujiang River, southwest China. Environmental Science \& Pollution Research International, 2013, 20 (7) : 4396-4404. DOI: 10.1007/s11356-013-1619-8.

[23] Li SX, Zhou LF, Wang HJ et al. Feeding habits and habitats preferences affecting mercury bioaccumulation in 37 subtropical fish species from Wujiang River, China. Ecotoxicology, 2009, 18(2) : 204-210. DOI: 10.1007/s10646-008-0273-2.

[24] Chi SY, Hu JX, Zhao XF et al. Assessment on water quality of Wujiang River by Percent Model Affinity. Yangtze River, 2011, 42(11) : 77-82. [ 池仕运, 胡菊香, 赵先富等. 乌江水质的百分比模式相似性指数评价. 人民长江, 2011, 42 (11): 77-82.]

[25] Halwas KL, Church M, Richardson JS. Benthic assemblage variation among channel units in high-gradient streams on Vancouver Island, British Columbia. Journal of the North American Benthological Society, 2005, 24(3) : 478-494. DOI: 10. 1899/0887-3593(2005)024[0478:BAVACU]2.0.CO;2.

[26] Leunda PM, Oscoz J, Miranda R et al. Longitudinal and seasonal variation of the benthic macroinvertebrate community and biotic indices in an undisturbed Pyrenean river. Ecological Indicators, 2009, 9(1) : 52-63. DOI: 10.1016/j.ecolind.2008. 01.009 .

[27] Novak MA, Bode RW. Percent model affinity: A new measure of macroinvertebrate community composition. Journal of the North American Benthological Society, 1992, 11(1) : 80-85. DOI: 10.2307/1467884.

[28] McCune B, Grace JB, Urban DL. Analysis of ecological communities. MjM software design Gleneden Beach, Oregon, 2002,28

[29] Ogbeibu A, Oribhabor B. Ecological impact of river impoundment using benthic macro-invertebrates as indicators. Water Research, 2002, 36(10) : 2427-2436. DOI: 10.1016/S0043-1354(01) 00489-4.

[30 ] Tiemann JS, Gillette DP, Wildhaber ML et al. Effects of lowhead dams on riffle-dwelling fishes and macroinvertebrates in a midwestern river. Transactions of the American Fisheries Society, 2004, 133(3) : 705-717. DOI: 10.1577/T03-058.1.

[31] Santucci JVJ, Gephard S, Pescitelli S. Effects of multiple low-head dams on fish, macroinvertebrates, habitat, and water quality in the Fox River, Illinois. North American Journal of Fisheries Management, 2005, 25(3) : 975-992. DOI: 10. 1577/M03-216.1.

[32] Doeg T, Davey G, Blyth J. Response of the aquatic macroinvertebrate communities to dam construction on the Thomson River, southeastern Australia. River Research \& Applications, 1987, 1(3) : 195-209. DOI: 10.1002/rrr.3450010302.

[33] Dessaix J, Fruget JF, Olivier JM et al. Changes of the macroinvertebrate communities in the dammed and by-pass sections of the French Upper Rhone after regulation. River Research \& Applications, 1995, 10: 265-279. DOI: 10. 1002/ rrr.3450100220.

[34] Bredenhand E, Samways M. Impact of a dam on benthic macroinvertebrates in a small river in a biodiversity hotspot: Cape Floristic Region, South Africa. Journal of Insect Conservation, 2009, 13 (3) : 297-307. DOI: 10. 1007/s10841-0089173-2.

[35] Zhang M, Cai QH, Qu XD. Macroinvertebrate succession and longitudinal zonation dynamics in Xiangxi Bay, after impoundment of the Three Gorges Reservoir. Acta Ecologica Sinica, 2017, 37 (13): 4483-4494. DOI: 10. 5846/ stxb201601130086. [张敏, 蔡庆华, 渠晓东等. 三峡成库后香溪河库湾底栖动物群落演变及库湾纵向分区格局动 态. 生态学报, 2017, 37(13): 4483-4494.]

[36] Shao M, Xie Z, Han X et al. Macroinvertebrate community structure in Three-Gorges Reservoir, China. International Review of Hydrobiology, 2008, 93(2) : 175-187. DOI: 10.1002/iroh.200710971.

[37] Zhang M, Shao M, Xu Y et al. Effect of hydrological regime on the macroinvertebrate community in Three-Gorges Reservoir, China. Quaternary International, 2010, 226(1) : 129-135. DOI: 10.1016/j.quaint.2009.12.019.

[38] Shao M, Xie Z, Ye L et al. Changes in the benthic macroinvertebrates in Xiangxi Bay following dam closure to form the 
Three Gorges Reservoir. Journal of Freshwater Ecology, 2006, 21(4) : 717-719. DOI: 10.1080/02705060.2006.9664135.

[39] Vaikasas S, Palaima KS, Pliūraite V. Influence of hydropower dams on the state of macroinvertebrates assemblages in the Virvyte river, Lithuania. Journal of Environmental Engineering \& Landscape Management, 2013, 21(4) : 305-315. DOI: 10.3846/16486897.2013.796956.

[40] Cushman RM. Review of ecological effects of rapidly varying flows downstream from hydroelectric facilities. North American Journal of Fisheries Management, 1985, 5: 330-339. DOI: 10.1577/1548-8659(1985) 5<330: ROEEOR>2.0.CO;2.

[41] Angulo-Preckler C, Leiva C, Avila C et al. Macroinvertebrate communities from the shallow soft-bottoms of Deception Island (Southern Ocean) : A paradise for opportunists. Marine Environmental Research, 2017, 127: 62-74. DOI: 10.1016/ j.marenvres.2017.03.008.

[42] Luo ZF, Fang ZQ. A study on the community structure of macrobenthos during the period of artificial mangrove restoration in Mangzhou wetland of Hengqin Island, Zhuhai. Journal of Tropical Oceanography, 2017, 36(3): 61-72. DOI: 10. 11978/2016088. [罗章风, 方展强. 珠海横琴岛芒洲湿地红树林人工恢复期大型底栖动物群落结构研究. 热带海 洋学报, 2017, 36(3): 61-72.]

[43] Sennatt KM, Salant NL, Renshaw CE et al. Assessment of methods for measuring embeddedness: Application to sedimentation in flow regulated streams. Journal of the American Water Resources Association, 2006, 42(6) : 1671-1682. DOI: 10. 1111/j.1752-1688.2006.tb06028.x.

[44] Petts GE, Greenwood M. Channel changes and invertebrate faunas below Nant-Y-Moch dam, River Rheidol, Wales, UK. Hydrobiologia, 1985, 122(1) : 65-80. DOI: 10.1007/BF00018961.

[45] Holt CR, Pfitzer D, Scalley C et al. Longitudinal variation in macroinvertebrate assemblages below a large-scale hydroelectric dam. Hydrobiologia, 2015, 755(1) : 1-14. DOI: 10.1007/s10750-015-2212-6.

[46] Baxter RM. Environmental effects of dams and impoundments. Annual Review of Ecology \& Systematics, 1977, 8(1): 255-283.

[47] Wang BQ, Liu XQ, Peng ZH et al. The community structure of zoobenthos in the Three Gorges Reservior: A comparison before and after the impoundment. Acta Hydrobiologica Sinica, 2015, 39(5) : 965-972. DOI: 10.7541/2015.126. [王宝 强, 刘学勤, 彭增辉等. 三峡水库底栖动物群落结构特征及其与蓄水前资料的比较. 水生生物学报, 2015, 39 (5) : 965-972.]

[48] Malmqvist B, Englund G. Effects of hydropower-induced flow perturbations on mayfly (Ephemeroptera) richness and abundance in north Swedish river rapids. Hydrobiologia, 1996, 341(2) : 145-158. DOI: 10.1007/BF00018118.

[49] Beckett DC, Miller MC. Macroinvertebrate colonization of multiplate samplers in the Ohio River: the effect of dams. Canadian Journal of Fisheries and Aquatic Sciences, 1982, 39(12) : 1622-1627. DOI: 10.1139/f82-218.

[50] Bosco IJ, Perry JA. Drift and benthic invertebrate responses to stepwise and abrupt increases in non-scouring flow. Hydrobiologia, 2000, 436(1) : 191-208. DOI: 10.1023/A:1026582218786.

[51] Tonkin JD, Death RG. Macroinvertebrate drift-benthos trends in a regulated river. Fundamental \& Applied Limnology, 2013, 182(3) : 231-245. DOI: 10.1127/1863-9135/2013/0404.

[52] Bond N, Lake PA. The impacts of drought on freshwater ecosystems: an Australian perspective. Hydrobiologia, 2008,600 (1) : 3-16. DOI: 10.1007/s10750-008-9326-z.

[53] McKinney T, Ayers AD, Rogers RS. Macroinvertebrate drift in the tailwater of a regulated river below Glen Canyon Dam, Arizona. The Southwestern Naturalist, 1999, 44(2) : 205-210.

[54] Troelstrup NH, Hergenrader GL. Effect of hydropower peaking flow fluctuations on community structure and feeding guilds of invertebrates colonizing artificial substrates in a large impounded river. Hydrobiologia, 1990, 199(3) : 217-228. DOI: 10.1007/BF00006354.

[55] Stanford JA, Ward J. Revisiting the serial discontinuity concept. Rivers Research \& Applications, 2001, 17 (4/5): 303310. DOI: $10.1002 /$ rrr.659.

[56] Ellis LE, Jones NE. Longitudinal trends in regulated rivers: a review and synthesis within the context of the serial discontinuity concept. Environmental Reviews, 2013, 21(3) : 136-148. DOI: 10.1139/er-2012-0064.

[57] Blyth J, Doeg T, St Clair R. Response of the macroinvertebrate fauna of the Mitta Mitta River, Victoria, to the construction and operation of Dartmouth Dam. 1. Construction and initial filling period. Occasional Papers from the Museum of Victoria, $1987, \mathbf{1}(2)$ : 83-100. 
[58] Katano I, Negishi JN, Minagawa T et al. Longitudinal macroinvertebrate organization over contrasting discontinuities: effects of a dam and a tributary. Journal of the North American Benthological Society, 2009, 28(2) : 331-351. DOI: 10. 1899/08-010.1.

[59] Snaddon K. Spatial and temporal changes in the riverine macroinvertebrate community composition in the Berg River, and the expected response following the development of the Berg River Dam. Transactions of the South African Philosophical Society, 2009, 64(2) : 119-141. DOI: 10.1080/00359190909519248.

[60] Munn MD, Brusven M. Discontinuity of trichopteran (caddisfly) communities in regulated waters of the Clearwater River, Idaho, USA. River Research \& Applications, 1987, 1(1) : 61-69. DOI: 10.1002/rrr.3450010107.

[61] Stevens LE, Shannon JP, Blinn DW. Colorado River benthic ecology in Grand Canyon, Arizona, USA: dam, tributary and geomorphological influences. River Research \& Applications, 1997, 13 (2) : 129-149. DOI: 10.1002/( SICI) 1099-1646 ( 199703$) 13: 23.0 . \mathrm{CO} ; 2-\mathrm{S}$.

[62] Armitage P, Blackburn J. Environmental stability and communities of Chironomidae (Diptera) in a regulated river. River Research \& Applications, 1990, 5(4) : 319-328. DOI: 10.1002/rrr.3450050404.

[63] Chessman B, Robinson D, Hortle K. Changes in the riffle macroinvertebrate fauna of the Tanjil River, southeastern Australia, during construction of Blue Rock Dam. River Research \& Applications, 1987, 1(4) : 317-329. DOI: 10.1002/ rrr.3450010404.

[64] Boon P. The impact of river regulation on invertebrate communities in the UK. River Research \& Applications, 1988, 2(3): 389-409. DOI: 10.1002/rrr.3450020314.

[65] Weisberg S, Janicki A, Gerritsen J et al. Enhancement of benthic macroinvertebrates by minimum flow from a hydroelectric dam. River Research and Applications, 1990, 5(3) : 265-277. DOI: 10.1002/rrr.3450050307.

[66] Gislason JC. Aquatic insect abundance in a regulated stream under fluctuating and stable diel flow patterns. North American Journal of Fisheries Management, 1985, 5(1) : 39-46. DOI : 10.1577/1548-8659(1985) 5<39: AIAIAR>2.0.CO;2. 
附录 I 研究区域底栖动物名录

Appendix I The list of macroinvertebrates in the study area

\begin{tabular}{|c|c|c|c|c|c|c|c|c|c|c|c|c|c|}
\hline \multirow[b]{2}{*}{ 类群 } & \multirow[b]{2}{*}{ 目 } & \multirow[b]{2}{*}{ 科 } & \multirow[b]{2}{*}{ 物种 } & \multicolumn{2}{|c|}{ 区域 1} & \multicolumn{2}{|c|}{ 区域 2} & \multicolumn{3}{|c|}{ 区域 3} & \multicolumn{3}{|c|}{ 区域 4} \\
\hline & & & & $\begin{array}{l}\text { 蓄水前 } \\
2006- \\
2007 \text { 年 }\end{array}$ & $\begin{array}{l}\text { 蓄水后 } \\
2008- \\
2016 \text { 年 }\end{array}$ & $\begin{array}{l}\text { 蓄水前 } \\
2006- \\
2007 \text { 年 }\end{array}$ & $\begin{array}{c}\text { 蓄水后 } \\
2008- \\
2016 \text { 年 }\end{array}$ & $\begin{array}{l}\text { 蓄水前 } \\
2006- \\
2007 \text { 年 }\end{array}$ & $\begin{array}{c}\text { 蓄水后 } \\
\text { 第一时期 } \\
2008- \\
2010 \text { 年 }\end{array}$ & $\begin{array}{c}\text { 蓄水后 } \\
\text { 第二时期 } \\
2011- \\
2016 \text { 年 }\end{array}$ & $\begin{array}{l}\text { 蓄水前 } \\
2006- \\
2007 \text { 年 }\end{array}$ & $\begin{array}{c}\text { 蓄水后 } \\
\text { 第一时期 } \\
2008- \\
2010 \text { 年 }\end{array}$ & $\begin{array}{c}\text { 蓄水后 } \\
\text { 第二时期 } \\
2011- \\
2016 \text { 年 }\end{array}$ \\
\hline \multirow[t]{18}{*}{ 软体动物 } & 真瓣鳃目 & 蚬科 & 河蚬 Corbicula fluminea & + & + & & + & + & + & + & & + & + \\
\hline & & 贻贝科 & 淡水壳菜 Limnoperna lacustris & + & + & + & + & + & + & & + & + & + \\
\hline & 基眼目 & 扁蜷螺科 & 扁蜷螺 Planorbidae sp. & & & & + & & & & & & + \\
\hline & & & 大脐圆扁螺 Hippeutis umbilicalis & & & & + & & + & & & + & \\
\hline & & & 凸旋螺 Gyraulus convexiusculus & & & & & & + & + & & & + \\
\hline & & 椎实螺科 & 小土蜗 Galba pervia & & & & & & & & & + & \\
\hline & & 膀胱螺科 & 尖膀胱螺 Physa acuta & & & & & & & + & & & + \\
\hline & 中腹足目 & 助蜷科 & 肋肯森螺 Senckenbergia pleuroceroides & & & + & + & & + & & + & + & + \\
\hline & & 田螺科 & 梨形环棱螺 Bellamya purificata & & & & & & & + & & & + \\
\hline & & & 球河螺 Rivularia globosa & + & & + & + & & + & + & & + & + \\
\hline & & 觹螺科 & 透明仿雕石螺 Lithoglyphopsis hyalinus & + & & & + & + & & + & & + & + \\
\hline & & & 卵圆仿雕石螺 Lithoglyphopsis ovatus & & & & + & + & + & + & + & + & + \\
\hline & & & 堇拟沼螺 Assiminea violacea & & & & + & & & & & & + \\
\hline & & & 拟钓螺 Tricula sp. & & & & & & + & & & + & \\
\hline & & & 长拟钉螺 Tricula elongata & & & & & & & + & & & \\
\hline & & 豆螺科 & 堇拟沼螺 Assiminea violacea & & & & & & + & & & & \\
\hline & & & 赤豆螺 Bithynia fuchsiana & + & & & & & & & + & & + \\
\hline & & 狭口螺科 & 光滑狭口螺 Stenothyra glabra & & & & & & & + & & + & + \\
\hline \multirow[t]{8}{*}{ 水生昆虫 } & 蜻蜓目 & 丽蟌科 & 丽蟌 Amphipterygidae sp. & & & + & & & & & & & \\
\hline & & 鼻蟌科 & 鼻蟌 Chlorocyphidae sp. & & & + & & & & & & & \\
\hline & & 蟌科 & 蟌 Coenagrionidae sp. & & & & & & & & & & + \\
\hline & & 春蜓科 & 春蜓 Gomphidae sp. & + & + & & & & & & & & \\
\hline & 鳞翅目 & 草蛽科 & 草蛽蛾 Crambidae sp. & + & & & & & & & & & \\
\hline & 半翅目 & 划蝽科 & 划蝽科 Corixidae sp. & & & & & & & + & & & \\
\hline & 鞘翅目 & 扁泥虫科 & 扁泥虫 Psephenidae sp. & + & & & & & & & & & \\
\hline & & 龙虫科 & 龙䖝 Dytiscidae sp. & & & & & & & + & & & \\
\hline
\end{tabular}


续附录 $\mathrm{I}$

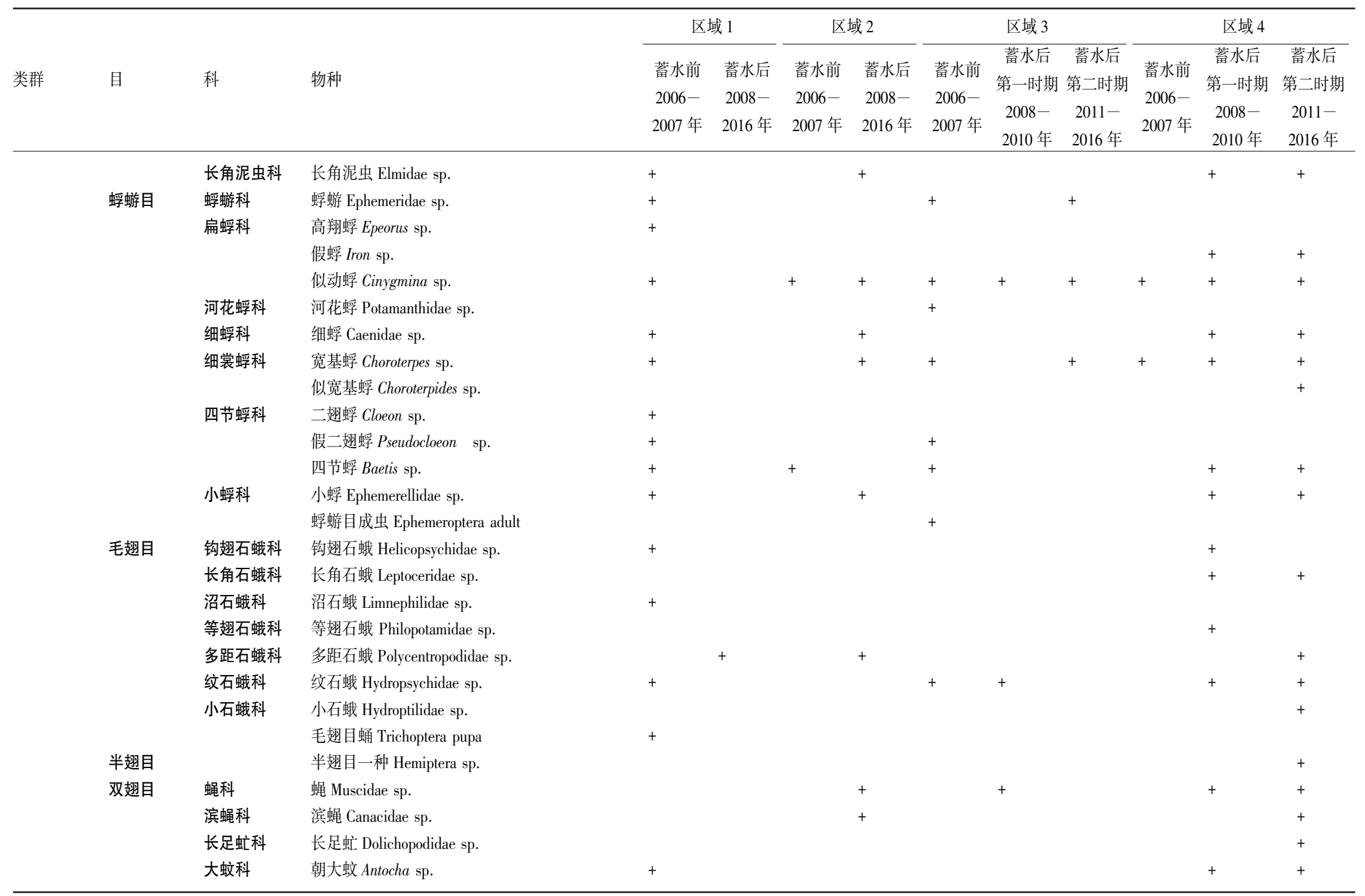


续附录 $\mathrm{I}$

\begin{tabular}{|c|c|c|c|c|c|c|c|c|c|c|c|c|c|}
\hline \multirow[b]{2}{*}{ 类群 } & \multirow[b]{2}{*}{ 目 } & \multirow[b]{2}{*}{ 科 } & \multirow[b]{2}{*}{ 物种 } & \multicolumn{2}{|c|}{ 区域 1} & \multicolumn{2}{|c|}{ 区域 2} & \multicolumn{3}{|c|}{ 区域 3} & \multicolumn{3}{|c|}{ 区域 4} \\
\hline & & & & $\begin{array}{l}\text { 蓄水前 } \\
2006- \\
2007 \text { 年 }\end{array}$ & $\begin{array}{l}\text { 蓄水后 } \\
2008- \\
2016 \text { 年 }\end{array}$ & $\begin{array}{l}\text { 蓄水前 } \\
2006- \\
2007 \text { 年 }\end{array}$ & $\begin{array}{l}\text { 蓄水后 } \\
2008- \\
2016 \text { 年 }\end{array}$ & $\begin{array}{l}\text { 蓄水前 } \\
2006- \\
2007 \text { 年 }\end{array}$ & 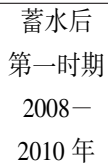 & $\begin{array}{c}\text { 蓄水后 } \\
\text { 第二时期 } \\
2011- \\
2016 \text { 年 }\end{array}$ & $\begin{array}{l}\text { 蓄水前 } \\
2006- \\
2007 \text { 年 }\end{array}$ & $\begin{array}{c}\text { 蓄水后 } \\
\text { 第一时期 } \\
2008- \\
2010 \text { 年 }\end{array}$ & 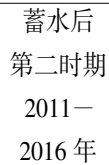 \\
\hline & & & 大蚊 Tipulidae sp. & & & & + & & & + & & + & + \\
\hline & & 亮大蚊科 & 亮大蚊 Dactylolabis sp. & & & & & & + & & & & \\
\hline & & 毛蠓科 & 毛蠓 Psychodidae sp. & & & & & & & & & & + \\
\hline & & 虻科 & 虹 Tabanidae sp. & & & & + & & & + & & & \\
\hline & & 蠓科 & 蠓 Ceratopogonidae sp. & & + & & + & & & + & & + & + \\
\hline & & 曲臂虹科 & 曲臂虹 Pelecorhynchidae sp. & + & & & & & & & & & \\
\hline & & 蚋科 & 蚋 Simuliidae sp. & + & & & & & & & & & \\
\hline & & 水虻科 & 水蚈 Stratiomyidae sp. & & & & + & & & + & & & + \\
\hline & & 水蝇科 & 水蝇 Ephydridae sp. & & & & & & & & & & + \\
\hline & & 伪獝虻科 & 伪敄蛙 Athericidae sp. & & & & + & & & & & & \\
\hline & & 摇蚊科 & 矮突摇蚊 Nanocladius sp. & & & & + & & & & & + & + \\
\hline & & & 雕翅摇蚊 Glyptotendipes sp. & & + & & & & & & & + & \\
\hline & & & 多足摇蚊 Polypedilum sp. & & + & & + & + & + & + & & + & + \\
\hline & & & 肚齿摇蚊 Neozavrelia sp. & & & & + & & & & & & \\
\hline & & & 环足摇蚊 Cricotopus sp. & + & & & + & & & + & & + & + \\
\hline & & & 开叉摇蚊 Dicrotendipes sp. & & & & + & + & & + & & & + \\
\hline & & & 克莱施密摇蚊 Krenosmittia sp. & & & & & & & & & & + \\
\hline & & & 林内摇蚊 Lipineilla sp. & & + & & & & & & & & \\
\hline & & & 菱跗摇蚊 Clinotanypus sp. & & + & & & & & + & & & \\
\hline & & & 流水长跗摇蚊 Rheotanytarsus sp. & + & + & & + & & & & & & + \\
\hline & & & 拟矩摇蚊 Paraphaenocladius sp. & & & & + & & & & & & + \\
\hline & & & 前突摇蚊 Procladius sp. & & + & & & & & + & & & + \\
\hline & & & 特维摇蚊 Tvetenia sp.1 & & & & + & & & & & & + \\
\hline & & & 特维摇蚊 Tvetenia sp.2 & & & & & & & & & & + \\
\hline & & & 小摇蚊 Microchironomus sp. & & + & & & & & + & & & \\
\hline
\end{tabular}




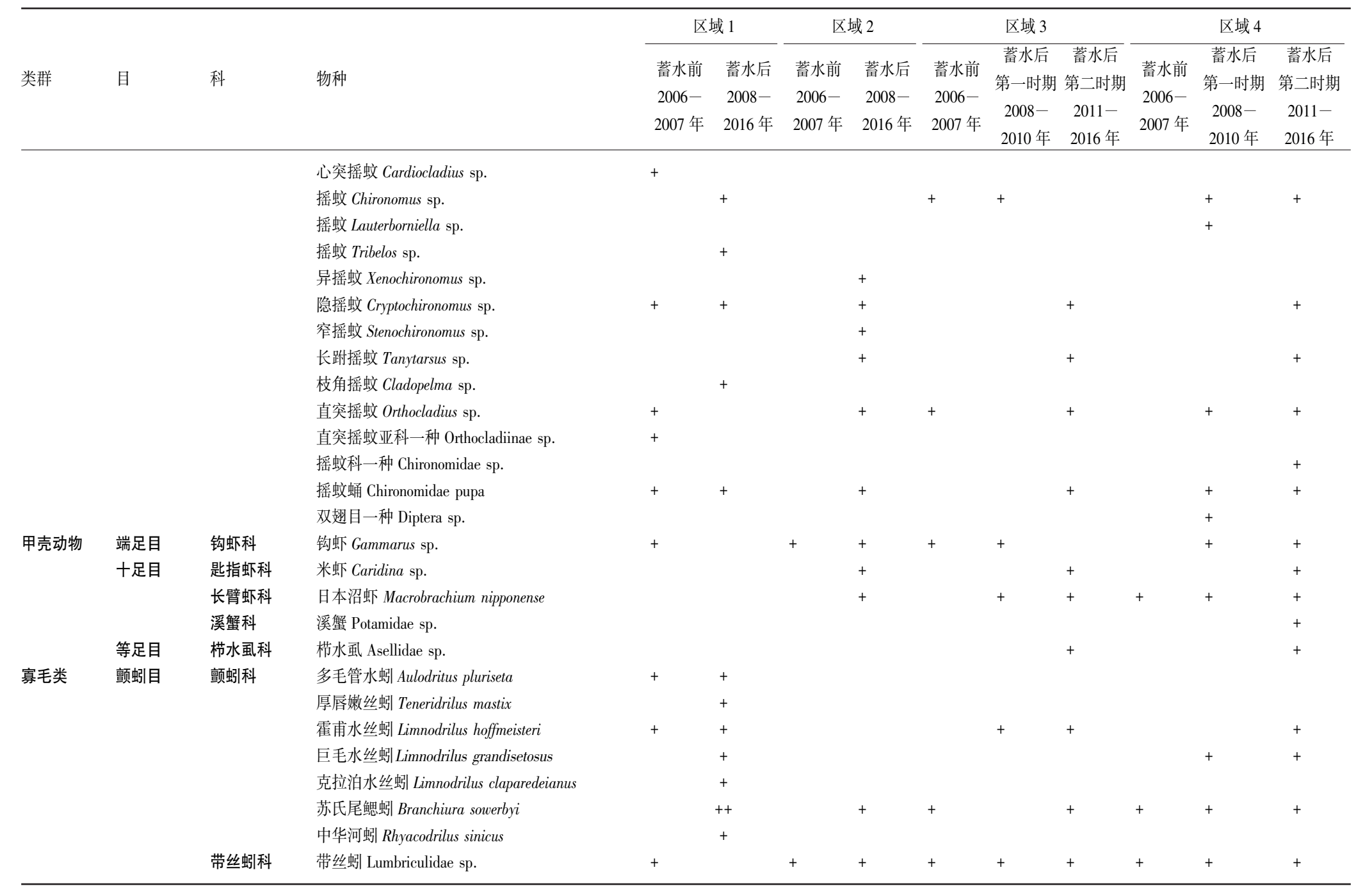




\begin{tabular}{|c|c|c|c|c|c|c|c|c|c|c|c|c|c|}
\hline \multirow[b]{2}{*}{ 类群 } & \multirow[b]{2}{*}{ 目 } & \multirow[b]{2}{*}{ 科 } & \multirow[b]{2}{*}{ 物种 } & \multicolumn{2}{|c|}{ 区域 1} & \multicolumn{2}{|c|}{ 区域 2} & \multicolumn{3}{|c|}{ 区域 3} & \multicolumn{3}{|c|}{ 区域 4} \\
\hline & & & & $\begin{array}{l}\text { 蓄水前 } \\
2006- \\
2007 \text { 年 }\end{array}$ & $\begin{array}{l}\text { 蓄水后 } \\
2008- \\
2016 \text { 年 }\end{array}$ & $\begin{array}{l}\text { 蓄水前 } \\
2006- \\
2007 \text { 年 }\end{array}$ & $\begin{array}{l}\text { 蓄水后 } \\
2008- \\
2016 \text { 年 }\end{array}$ & $\begin{array}{l}\text { 蓄水前 } \\
2006- \\
2007 \text { 年 }\end{array}$ & $\begin{array}{c}\text { 蓄水后 } \\
\text { 第一时期 } \\
2008- \\
2010 \text { 年 }\end{array}$ & $\begin{array}{c}\text { 蓄水后 } \\
\text { 第二时期 } \\
2011- \\
2016 \text { 年 }\end{array}$ & $\begin{array}{l}\text { 蓄水前 } \\
2006- \\
2007 \text { 年 }\end{array}$ & $\begin{array}{c}\text { 蓄水后 } \\
\text { 第一时期 } \\
2008- \\
2010 \text { 年 }\end{array}$ & $\begin{array}{c}\text { 蓄水后 } \\
\text { 第二时期 } \\
2011- \\
2016 \text { 年 }\end{array}$ \\
\hline & & 仙女虫科 & $\begin{array}{l}\text { 豹行仙女虫 Nais pardalis } \\
\text { 亚洲尾盘虫 Dero asiatica }\end{array}$ & & & & & & & $\begin{array}{l}+ \\
+\end{array}$ & & & + \\
\hline 其他类群 & $\begin{array}{l}\text { 吻蛭目 } \\
\text { 无吻蛭目 }\end{array}$ & $\begin{array}{l}\text { 舌蛭科 } \\
\text { 石蛭科 }\end{array}$ & $\begin{array}{l}\text { 舌蛭 Glossiphoniidae sp. } \\
\text { 石蛭 Erpobdellidae sp. } \\
\text { 浴虫 Turbellaria sp. } \\
\text { 线虫 Nematoda sp. }\end{array}$ & + & + & & & & + & + & & $\begin{array}{l}+ \\
+\end{array}$ & $\begin{array}{l}+ \\
+\end{array}$ \\
\hline
\end{tabular}

